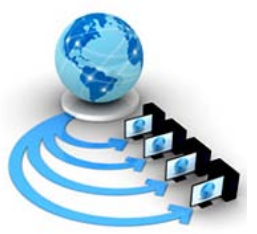

Volume 9, No. 2, March-April 2018

\title{
MEDITATION AS THERAPY: FRACTAL STUDY USING ECG TIME SERIES
}

\author{
Dr. Monisha Chakraborty \\ Associate Professor, School of Bio-Science \& Engineering \\ Jadavpur University \\ Kolkata-700032, India
}

\begin{abstract}
This work reports on the study of the effects of meditation as stimulus on six subjects. Their ECG signals are acquired before and while on meditation. The ECG time series are analysed in the light of fractal based nonlinear technique. For this purpose Hurst's Rescaled range analysis method has been utilized. The results are interesting and may be useful in the development of meditation therapy.
\end{abstract}

Keywords: meditation; therapy; ECG time series; fractal; non-linear technique; Hurst’s Rescaled range analysis method

\section{INTRODUCTION}

Meditation techniques are coming up as a psychological intervention to deal with several conditions including stress, chronic pain and anxiety [1, 2]. Mindfulness meditation modulates the stage of thoughts. It reduces the analytical burden. It prevents obsessive and discursive thoughts [3]. Meditation helps to pacify the thought process and it also helps to practice self-control. Reductions of stress and anxiety can be detected by studying changes in skin conductivity [4]. Wallace in a study showed that meditation is accompanied by changes in oxygen consumption, heart rate, skin resistance, and power of certain EEG frequencies [5]. Research activities are in the area to find the functional links between meditation and the activity of the autonomic nervous system (ANS) via fMRI monitoring [4] , heart rate variability studies [6] , sleep studies [7] , endocrine system response [8] etc. Parameters related ANS activity are considered as biomarkers for monitoring the states of meditation $[4,9,10]$. Neuro-imaging techniques are very efficient methods for monitoring the dynamics of meditation. But, they are expensive and such methods are disturbing during the session of meditation. This makes these methods not very acceptable to study the meditation stages and the dynamics related to that. Meditation changes some physiological states through autonomic control actions and as such it has immense effects on ANS [11]. ANS regulates the heart rate via sympathetic and parasympathetic networks.

Electrocardiogram (ECG) is the record of the electrical activity of the heart. Different kinds of external stimulation on heart activity can be studied by analyzing the ECG signal. Emotion elicited by olfactory stimuli [12-15] is noteworthy to mention. ANS can be minutely studied with ECG time series. The nature of ECG signals is nonlinear and complex. ECG signal has self-similarity or Fractal nature. A fractal exhibits a repeating pattern or self-similar pattern revealing at every scale. Scaling exponents or fractal dimension decides the scaling rules. Complex self-similar objects have non-integer dimension. In this work, effect of meditation on ANS has been studied. For this purpose, ECG signals are acquired from six subjects. Methods based on
DSP techniques are sometimes unable to decode the complexity of non-linear signal modified by the input of emotion elicited stimuli. Fractal approach is very sensitive to address such intricate complexities in signals. In this work, Hurst's Rescaled Range Analysis method [16-17] has been utilized which focuses on finding the Fractal Dimension of the time varying ECG signal.

\section{EXPERIMENTAL METHOD}

ECG signals are recorded using an instrument POLYPARA module with a sampling rate of 200 samples per second from 6 participants. All of them are under no medical treatment. All participants are allowed to sit in a relaxed position. Normal ECG signals are recorded for 5 minutes. They are then allowed to relax for 15 minutes. Each subject is then put under meditation session separately while ECG signals are recorded for 5 minutes.

\section{STATistical METHOD}

\section{A. Hurst's Rescaled Analysis}

This is a non-parametric method for finding Hurst exponent $(\mathrm{H})$ and Fractal Dimension (D) of a time series [1617]. The discrete ECG time series data set $x_{t}$ is of dimension N. Mean $\tilde{x}(N)$; standard deviation $\mathrm{S}(\mathrm{N})$ and cumulative departure $X(n, N)$, are calculated using the equations as given below [16-17],

$$
\begin{aligned}
& \tilde{\boldsymbol{x}}(\boldsymbol{N})=\sum \frac{\boldsymbol{x}_{\boldsymbol{t}}}{\boldsymbol{N}} \\
& S(N)=\left[\frac{1}{N} \sum\left(x_{t}-\tilde{x}(N)\right)^{2}\right]^{\frac{1}{2}}
\end{aligned}
$$

Range of cumulative departure of the data is

$\mathrm{R}(\mathrm{N})=\max [\mathrm{x}(\mathrm{n}, \mathrm{N})]-\min [\mathrm{x}(\mathrm{n}, \mathrm{N})]$

Where cumulative departure is given by

$$
X(n, N)=\sum\left(x_{t}-\tilde{x}(N)\right), \quad 0 \leq \mathrm{n} \leq \mathrm{N}
$$




$$
\frac{R}{S}=n^{H}
$$

The fractal dimension D [16-17] is determined as

$$
\mathrm{D}=2-\mathrm{H}
$$

The ECG time series is persistent if the value of Hurst exponent lies in between 0.5 and 1 [18-19]. On the other hand, if Hurst exponent lies in between 0 and 0.5, then the
ECG time series is anti-persistent [18-19]. In this work, all the ECG time series are divided into five sections. Each of these sections is of 5000 samples in length. Hurst Rescaled range analysis method is applied on each of the section of these ECG time series and $\mathrm{H}$ and $\mathrm{D}$ values for each section are tabulated in the following tables.

Table 1: Hurst Exponent (H) and Fractal Dimension (D) for Normal ECG

\begin{tabular}{|c|r|c|c|c|r|r|r|r|c|c|}
\hline Subject & \multicolumn{2}{|c|}{$\begin{array}{c}1^{\text {st }} \text { slot of } 5000 \\
\text { samples }\end{array}$} & \multicolumn{2}{c|}{$\begin{array}{c}2^{\text {nd }} \text { slot of } 5000 \\
\text { samples }\end{array}$} & \multicolumn{2}{c|}{$\begin{array}{c}3^{\text {rd }} \text { slot of } 5000 \\
\text { samples }\end{array}$} & \multicolumn{2}{c|}{$\begin{array}{c}4^{\text {th }} \text { slot of } 5000 \\
\text { samples }\end{array}$} & \multicolumn{2}{c|}{$\begin{array}{c}5^{\text {th }} \text { slot of } 5000 \\
\text { samples }\end{array}$} \\
\cline { 2 - 13 } & $\mathrm{H}$ & $\mathrm{D}$ & $\mathrm{H}$ & $\mathrm{D}$ & $\mathrm{H}$ & $\mathrm{D}$ & $\mathrm{H}$ & $\mathrm{D}$ & $\mathrm{H}$ & $\mathrm{D}$ \\
\hline 1 & 0.6174 & 1.3826 & 0.4059 & 1.5941 & 0.4034 & 1.5966 & 0.3992 & 1.6008 & 0.3973 & 1.6027 \\
\hline 2 & 0.6357 & 1.3643 & 0.5548 & 1.4452 & 0.5366 & 1.4634 & 0.5973 & 1.4027 & 0.5123 & 1.4877 \\
\hline 3 & 0.5587 & 1.4413 & 0.5344 & 1.4656 & 0.5393 & 1.4607 & 0.5186 & 1.4814 & 0.5441 & 1.4559 \\
\hline 4 & 0.5215 & 1.4785 & 0.3499 & 1.6501 & 0.3596 & 1.6404 & 0.3554 & 1.6446 & 0.3690 & 1.6310 \\
\hline 5 & 0.5078 & 1.4922 & 0.3535 & 1.6465 & 0.3353 & 1.6647 & 0.3356 & 1.6644 & 0.3322 & 1.6678 \\
\hline 6 & 0.5863 & 1.4137 & 0.4290 & 1.571 & 0.4298 & 1.5702 & 0.4203 & 1.5797 & 0.4187 & 1.5813 \\
\hline
\end{tabular}

\begin{tabular}{|c|c|c|c|c|c|c|c|c|c|c|}
\hline \multirow[t]{2}{*}{ Subject } & \multicolumn{2}{|c|}{$\begin{array}{c}1^{\text {st }} \text { slot of } 5000 \\
\text { samples }\end{array}$} & \multicolumn{2}{|c|}{$\begin{array}{c}2^{\text {nd }} \text { slot of } 5000 \\
\text { samples }\end{array}$} & \multicolumn{2}{|c|}{$\begin{array}{c}3^{\text {rd }} \text { slot of } 5000 \\
\text { samples }\end{array}$} & \multicolumn{2}{|c|}{$\begin{array}{c}4^{\text {th }} \text { slot of } 5000 \\
\text { samples }\end{array}$} & \multicolumn{2}{|c|}{$\begin{array}{c}5^{\text {th }} \text { slot of } 5000 \\
\text { samples }\end{array}$} \\
\hline & $\mathrm{H}$ & $\mathrm{D}$ & $\mathrm{H}$ & $\mathrm{D}$ & $\mathrm{H}$ & $\mathrm{D}$ & $\mathrm{H}$ & $\mathrm{D}$ & $\mathrm{H}$ & $\mathrm{D}$ \\
\hline 1 & 0.6175 & 1.3825 & 0.4067 & 1.5933 & 0.412 & 1.588 & 0.4111 & 1.5889 & 0.4099 & 1.5901 \\
\hline 2 & 0.6271 & 1.3729 & 0.4447 & 1.5553 & 0.4408 & 1.5592 & 0.4409 & 1.5591 & 0.4551 & 1.5449 \\
\hline 3 & 0.6054 & 1.3946 & 0.5424 & 1.4576 & 0.5453 & 1.4547 & 0.5375 & 1.4625 & 0.5383 & 1.4617 \\
\hline 4 & 0.5322 & 1.4678 & 0.3653 & 1.6347 & 0.3631 & 1.6369 & 0.3754 & 1.6246 & 0.3635 & 1.6365 \\
\hline 5 & 0.5573 & 1.4427 & 0.367 & 1.633 & 0.38 & 1.62 & 0.3813 & 1.6187 & 0.3692 & 1.6308 \\
\hline 6 & 0.6307 & 1.3693 & 0.4197 & 1.5803 & 0.4413 & 1.5587 & 0.4261 & 1.5739 & 0.4353 & 1.5647 \\
\hline
\end{tabular}

Table 2: Hurst Exponent (H) and Fractal Dimension (D) for ECG with Meditation as Stimulus

From Table 1 and Table 2, some interesting observations are made. There is an increasing trend of persistent nature with meditation as stimulus in the first and fifth subjects over all the time slots. The second subject has shown decreasing trend of persistent nature with meditation as stimulus over all the time slots. Third and fourth subjects have shown increasing trend of persistent nature with meditation as stimulus over all time slots except in the last one. Sixth subject has shown increasing trend of persistent nature with meditation as stimulus over all time slots except in the second time slot. These facts indicate the intricate complexity of ECG time series with meditation as stimulus over all the five time slots. 
Table 3: Average values of $\mathrm{H}$ and $\mathrm{D}$ of six subjects

\begin{tabular}{|c|r|r|r|r|}
\hline \multirow{2}{*}{ Subject } & \multicolumn{2}{|c|}{ Normal ECG } & \multicolumn{2}{c|}{ ECG with Meditation } \\
\cline { 2 - 5 } & $\mathrm{H}$ & $\mathrm{D}$ & $\mathrm{H}$ & $\mathrm{D}$ \\
\hline 1 & 0.44464 & 1.55536 & 0.45144 & 1.54856 \\
\hline 2 & 0.56734 & 1.43266 & 0.48172 & 1.51828 \\
\hline 3 & 0.53902 & 1.46098 & 0.55378 & 1.44622 \\
\hline 4 & 0.39108 & 1.60892 & 0.39990 & 1.60010 \\
\hline 5 & 0.37288 & 1.62712 & 0.41096 & 1.58904 \\
\hline 6 & 0.45682 & 1.54318 & 0.47062 & 1.52938 \\
\hline
\end{tabular}

From Table 3 it is observed that first, fourth, fifth and sixth subjects have shown anti-persistent nature before meditation. While on meditation, each of them is showing anti-persistent nature but the trend is moving towards persistency. This implies meditation has caused their ECG signals to move towards regular patterns and smoothness. The third subject has persistent nature before meditation and moreover this subject is showing more persistency while on meditation. So, this subject

\section{CONCLUSION}

The effect of meditation has shown an increasing trend towards persistency of ECG time series for the five subjects. One of the subjects has shown opposite trend. These results indicate that meditation has a relaxant effect and as such this method can be considered as a tool for meditation therapy.

\section{REFERENCES}

[1] Hofmann SG, Sawyer AT, Witt AA, Oh D. The effect of mindfulness-based therapy on anxiety and depression: a meta-analytic review. J Consult Clinical Psychol 2010;78:169-83. doi: 10.1037/a0018555 .

[2] Streeter CC, Gerbarg PL, Saper RB, Ciraulo DA, Brown RP. Effects of yoga on the autonomic nervous system, gamma-aminobutyric-acid, and allostasis in epilepsy, depression, and post-traumatic stress disorder. Med Hypotheses 2012;78:571-9. doi: 10.1016/j.mehy.2012.01.021 .

[3] Shapiro S . Meditation and positive psychology. In: Lopez SJ, Snyder CR, editors. Oxford Handbook of Positive Psychology. Oxford: Oxford University Press; 2009. p. 601-10 .

[4] Tang YY, Ma Y, Fan Y, Feng H, Wang J, Feng S, et al.. In: Central and autonomic nervous system interaction is altered by short-term meditation, 106; 2009. p. 8865-70. doi: 10.1073/pnas.0904031106 .

[5] Wallace RK. Physiological effects of transcendental meditation. Science 1970;167:1751-4. doi: 10.1126/science.167.3926.1751

[6] Phongsuphap S, Pongsupap Y, Chandanamattha P, Lursinsap C. Changes in heart rate variability during concentration meditation. Int. J Cardiol 2008;130:481-4. doi: 10.1016/j.ijcard.2007.06.103 .

[7] Nagendra RP, Maruthai N, Kutty BM. Meditation and its regulatory role on sleep. Front Neurol 2012;3(54):1-4. doi: 10.3389/fneur.2012.0 0054 .

[8] Fernandes CA, Nóbrega YK, Tosta CE. Pranic meditation affects phagocyte functions and hormonal levels of recent has also shown that meditation has caused the ECG signal to move towards regular patterns and smoothness. The second subject on the other hand has shown persistent nature before meditation. But, this subject has shown anti-persistent nature while on meditation. So, this subject has shown opposite result that is meditation has caused the ECG time series to become more complex and it has moved towards irregular patterns.

practitioners. J Altern Complement Med 2012;18:761-8. doi: 10.1089/acm.2010.0718 .

[9] Jerath R, Edry JW, Barnes VA, Jerath V. Physiology of long pranayamic breathing: neural respiratory elements may provide a mechanism that explains how slow deep breathing shifts the autonomic nervous system. Med Hypotheses 2006;67:566-71. doi: 10.1016/j.mehy.2006.02.042 .

[10] Peressutti C, Martín-González JM, García-Manso JM, Mesa D. Heart rate dynamics in different levels of Zen meditation. Int J Cardiol 2010;145:142-6. doi: 10.1016/j.ijcard.2009.06.058 .

[11] Tang YY, Ma Y, Wang J, Fan Y, Feng S, Lu Q, et al.. In: Short-term meditation training improves attention and self-regulation, 104 ; 2007 . p. 17152-6. doi: 10.1073/pnas.0707678104

[12] J. Alvarez-Ramirez, E. Rodríguez, J.C. Echeverría, Fractal scaling behavior of heart rate variability in response to meditation techniques, Chaos, Solitons and Fractals 99 (2017) 57-62

[13] aNarendra Jadhav, Ramchandra Manthalkar, Yashwant Joshi, Effect of meditation on emotional response: An EEG-based study, Biomedical Signal Processing and Control 34 (2017) 101-113

[14] Matthieu Ricard, Antoine Lutz, Richard J. Davidson, Mind of the meditator, Sci.Am. 311 (5) (2014) 38-45.

[15] W. John Thomas, Marc Cohen, A methodological review of meditationresearch, Front. Psychiatry 5 (2014)

[16] Hurst H.E.(1951).Long term storage capacity of reservoirs, Trans. Am. Soc. Civ. Eng, 116, pp-770-808.

[17] Feder J.(1998).Fractals. Plenum Press, NY, 283.

[18] N.K. Das, P. Sen, R.K. Bhandari, Bikash Sinha; "Non linear response of Radon its Progeny in Spring Emission"; Applied Radiation and Isotopes, Elsevier, 67, pp-313-318, 2009

[19] Dipak Chandra Ghosh, Monisha Chakraborty and Tithi Das, Fractal Approach to Identify Quantitatively Intracardiac Atrial Fibrillation from ECG Signals, International Journal of Engineering Research and Application, Vol. 3, Issue 5, Sep-Oct 2013, pp.129-134 